\title{
On the theoretical implications of Cypriot Greek initial geminates
}

\author{
Jennifer S. Muller \\ The Ohio State University
}

Cypriot Greek contrasts singleton and geminate consonants in word-initial position. These segments are of particular interest to phonologists since two divergent representational frameworks, moraic theory (Hayes 1989) and timing-based frameworks, including CV or X-slot theory (Clements and Keyser 1983, Levin 1985), account for the behavior of initial geminates in substantially different ways. The investigation of geminates in Cypriot Greek allows these differences to be explored. As will be demonstrated in a formal analysis of the facts, the patterning of geminates in Cypriot is best accounted for by assuming that the segments are dominated by abstract timing units such as X- or C-slots, rather than by a unit of prosodic weight such as the mora.

Keywords: geminates, representation, phonology, Cypriot Greek

\section{Introduction}

Cypriot Greek is of particular interest, not only because it is one of the few varieties of Modern Greek maintaining a consonant length contrast, but more importantly because it exhibits this contrast in word-initial position: péfti 'Thursday' vs. $p p e ́ f t i$ 'he falls'. Although word-initial geminates are less common than their word-medial counterparts, they are attested in dozens of the world's languages in addition to Cypriot Greek. For example, these segments are observed in the Austronesian languages Chuukese (Goodenough and Sugita 1980), Leti (van Engelenhoven 1996), and Sa'ban (Clayre 1973); in the IndoEuropean languages Faetar (Kattenbusch 1982), Breton (Carlyle 1988) and Bernese Swiss (Ham 1998); in the Caucasian languages Georgian (Hewitt 1995) and Lak (Anderson 1997), in the Mon-Khmer languages Jeh (Cohen 1965) and Nhauhen (Jacq, p.c.), in the Niger-Congo language Pulaar (Niang 1997), in the 
Bantu language Luganda (Clements 1986), the Afro-Asiatic language Berber (Dell and Elmedlaoui 1985), and in the Japanese Ryukyuan language Hatoma (Lawrence, p.c.) among others (see Muller 2001b, for further discussion).

The fact that word-initial geminates are so widely attested is significant for any discussion of phonological representation. In general, contemporary prosodic frameworks have been developed without the benefit of data from languages with initial geminates. As a result, some of these frameworks face difficulties in accounting for the behavior of these segments, as will be presented in more depth below. While it may be tempting to ascribe this difficulty to the rare and anomalous nature of initial geminates, the sheer number of languages with these segments indicates that the issues cannot be ignored.

As will be demonstrated, the facts of Cypriot Greek suggest that a prosodic representation that includes the explicit representation of timing slots is best able to account for the observed patterns in a straightforward way. Specifically, it will be demonstrated in Section 3 that the Cypriot Greek pattern is best accounted for under the assumption that all segments are dominated by an abstract timing unit, along the lines of Clements and Keyser's 1983 CV theory, or Levin's 1985 $\mathrm{X}$-slot theory. By comparison, the moraic theory framework (Hayes 1989) is shown to be inefficient in accounting for the facts of this language.

The phonological and phonetic characteristics of geminates in Cypriot Greek have been investigated in various works (Hamp, 1961; Newton, 1967, 1972; Malikouti-Drachman 1987; Arvaniti \& Tserdanelis 2000; Tserdanelis \& Arvaniti 2001; Muller 2001a). Malikouti-Drachman (1987) showed that the Cypriot geminates are best represented as single melodic units which are multiply-linked to two prosodic positions, findings that are mirrored in the present discussion. However, at the time of Malikouti-Drachman's analysis, moraic theory had not yet been presented as a framework that could supplant the timing-based model, and so the implications that the Cypriot geminates hold for the different representational frameworks could not be explored. In the current discussion, this topic is addressed, and it is shown that a model which includes the explicit representation of timing slots allows for a more elegant account of the facts. Thus, the perspective offered in the current investigation serves to provide additional support to the conclusions of Malikouti-Drachman (1987).

In a more recent analysis of the Cypriot geminates and their implications for phonological representation (Arvaniti 2001), phonetic data is cited as evidence that geminates in this language are represented via timing slots and not a moraic structure. Although Arvaniti supports the same conclusion as that 
of the present analysis, there are fundamental differences in how this conclusion is reached which are worth noting.

Specifically, it is posited in the earlier analysis that since geminates do not cause any significant shortening of a preceding vowel, they cannot be associated to a mora. Crucially, it is assumed that there is a direct relationship between the mora and the actual manifestation of phonetic duration, an assumption which, while shared by various researchers (e.g. Broselow et al. 1997, Ham 1998), is not uncontroversial. While there may be a relationship between the abstract concept of weight and phonetic manifestation, this relationship is not direct. For example, durational differences may result from factors other than moraic structure (such as the durational differences exhibited in English vowels before voiced and voiceless stops). Furthermore, the presence of a mora does not necessarily imply anything about phonetic duration, as evidenced by Chuukese (see Muller 1999). In this language, evidence from a prosodic minimality process indicates that initial geminates are moraic (nouns must be bimoraic; a form such as [t:o] 'clam' satisfies this requirement). However, the presence of the mora is phonetically meaningless for these segments. The geminate stops in Chuukese are all voiceless, meaning that there is no vocal cord vibration during their articulation, and they are essentially silent. When the stops are in utterance-initial position, they are preceded by silence. Since they are characterized by silence themselves, there is no way then to establish their actual duration. In studies of initial voiceless geminates in Pattani Malay, Abramson (1992) has found that speakers encode phonological length of initial segments via acoustic features other than duration (such as increased RMS amplitude). Similarly, in a study of the initial geminates of Cypriot Greek, Muller (2001a) finds that phonological length is encoded via increased VOT values, a signal listeners are able to cue in on. Thus, it is apparent that the presence (or absence) of the abstract prosodic unit, the mora, does not necessarily correlate with phonetic manifestation.

In the present analysis, the evidence that Cypriot geminates are best represented via timing slots rather than moras comes primarily from the phonological patterns exhibited by these sounds, specifically that while they act like single, monolithic segments, they also pattern like consonant clusters for some processes. Further support that this type of representation is appropriate for Cypriot is based on more general considerations. It is argued that a representation which includes timing slots is superior to one which assumes only moras, since only the timing-slot model treats initial geminates and consonant clusters as a natural class. Since geminates and clusters are observed to pattern 
alike in many languages (see e.g. Muller 2001b; Ham 1998, and references therein), this aspect of timing-slot models is argued to be a theoretical advantage - not only for Cypriot Greek, but for any language in which initial geminates and consonant clusters pattern alike.

\section{Data}

\subsection{Background and basic facts}

The data presented in this paper come from a reference grammar (Newton, 1972), as well as a native Cypriot language informant; all of the data has been checked with that speaker. Geminates are common in Cypriot Greek and are found throughout the language, in both native and borrowed words. These segments are found in both word-medial and word-initial position, as shown below:

(1) a. word-medial consonant length contrast

$\begin{array}{llll}\text { xapárin } & \text { 'piece of news' } & \text { apparín } & \text { 'horse' } \\ \text { túti } & \text { 'this girl' } & \text { mútti } & \text { 'nose' } \\ \text { pléki } & \text { 'she knits' } & \text { purékkin } & \text { 'pastry' } \\ \text { kaká } & \text { 'bad' } & \text { kakká } & \text { 'feces' } \\ \text { word-initial consonant length contrast } & \\ \text { péfti } & \text { 'Thursday' } & \text { ppéfti } & \text { 'he falls' } \\ \text { távla } & \text { 'table' } & \text { ttávlin } & \text { 'backgammon' } \\ \text { kiría } & \text { 'Mrs. } & \text { kkirás } & \text { 'rent' } \\ \text { kullúrka } & \text { 'rolls' } & \text { kkuláfka } & \text { 'flattery' }\end{array}$

\subsection{Geminates as single segments}

Evidence suggesting that Cypriot Greek geminates are single segments, rather than sequences of two identical segments, comes from a variety of sources. One type of evidence comes from a palatalization process. In Cypriot Greek, segments may be realized as palatals before the front vowel /i/. As shown in (2a), the velar stop and fricative are realized as palatals in this environment. As shown in $(2 b)$, when a geminate is in this environment, the entire segment undergoes palatalization. In contrast, when a consonant cluster precedes a high vowel, as in the final example, only the second segment is subject to palatalization; the first segment in the cluster is unaffected. 
(2) Palatalization ${ }^{1}$
a. kakós
'bad (MASC.sG)'
kačí
'bad (FEM.SG)' tíxos 'wall (NOM.SG)'
tíši
'walls (NOM.PL)'
b. sákkos
'jacket (NOM.sG)'
sáčči
'jacket (NOM.PL)'
*sakči
c. marankós
'carpenter (NOM.sG)'
maranči
'carpenter (NOM.PL)'
*marañči

If geminates were sequences of two identical segments rather than a single monolithic segment, their behavior with regard to palatalization would be inexplicable. Specifically, in the preceding examples, a form in which only the second 'half' of the geminate is palatalized would be expected if these segments were really sequences. However, if geminates are posited to be single units, the observed pattern is unsurprising.

Additional evidence which is suggestive that geminates are single segments in Cypriot Greek comes from phonotactic restrictions in the language. First, the distribution of stop clusters within words is severely restricted: only /pk/ and /pt/ are observed, out of all possible stop combinations (/pt/, /pk/, /tp/, /tk/, $/ \mathrm{kp} /, / \mathrm{kt} /)^{2}{ }^{2}$ The stop clusters that are observed are rare. For example, review of a Cypriot dictionary (Giagoulles 1994) reveals only about a dozen examples of the /pk/ cluster, and less than a half-dozen examples of the /pt/ cluster. Furthermore, /pt/ is restricted to the word-medial environment. In contrast, the geminate stops of Cypriot are not subject to such restrictions: all are observed in word-medial and word-initial position, in dozens of examples. If the geminates of Cypriot were posited to be sequences of identical stops, their wide distribution would be difficult to account for in light of the restrictions on the other stop clusters. Conversely, if the geminates are taken as single segments, their distributional patterns are unproblematic.

Patterns exhibited in morpheme concatenation also indicate that stop clusters are dispreferred in Cypriot Greek. Specifically, when stems with final stops precede the perfective past suffix /-tin/, the stop is lenited, as demonstrated in (3). If the stem-final segment were unaltered, a stop cluster would result as indicated in the starred examples. The lenition process only occurs in this environment and we thus assume that this results from a general prohibition against clusters of this type. ${ }^{3}$

(3) Stem-final consonant alternation ${ }^{4}$

$\begin{array}{lll}\text { Proposed stem } & \text { (Newton 1972) Perfective past passive /-tin/ } \\ \text { /vlap/ } & \text { 'hurt' } & \text { efláftin *efláptin }\end{array}$




\section{/pemp/ 'send' epéftin *epéptin \\ /sfank/ 'slaughter' esfáxtin *esfáktin \\ cf. /sfank/ + perfective past active suffix /sen/ $\rightarrow$ esfáksin * esfáxsin.}

It is crucial to note that there are no processes which lenite the initial part of a geminate consonant, demonstrating that geminates do exhibit behavior unlike clusters:

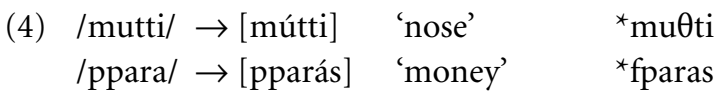

If geminates were taken to be sequences of identical segments, the patterns described above would be difficult to explain, since a 'cluster' of stops such as $/ \mathrm{pp} /$ is allowed, while a cluster such as /pt/ is not. However, if it is assumed that geminates are single segments, these patterns become clear. Stop clusters are avoided; geminates are unaffected by this prohibition because they are single segments and not real clusters.

\subsection{Geminates patterning as consonant clusters}

While geminates behave as single segments for some processes, they also pattern like consonant clusters for others. A clear example comes from the process of final nasal deletion across word boundaries.

As demonstrated in the examples below, the final nasal consonant of the articles/tin/ and /ton/ surfaces unaffected when followed by a word that begins with a vowel or a single consonant. ${ }^{5}$ As illustrated in (b), when the second word has an initial geminate consonant, the nasal is deleted. Similarly, when the second word begins with an onset cluster, the nasal may also be deleted, as shown in (c). However, as demonstrated by the examples in (d), the nasal is not deleted before all types of word-initial consonant clusters. Specifically, the clusters that do not trigger deletion consist of stops followed by liquids.

(5) Nasal deletion

\begin{tabular}{|c|c|c|}
\hline $\begin{array}{l}\text { a. ton ápparon } \\
\text { ton tíxon } \\
\text { tin petterán }\end{array}$ & $\begin{array}{l}\text { 'the horse' } \\
\text { 'the wall' } \\
\text { 'the mother-in-law' }\end{array}$ & $\begin{array}{l}{ }^{*} \text { to ápparon } \\
{ }^{*} \text { to tíxon } \\
{ }^{*} \text { ti petterán }\end{array}$ \\
\hline $\begin{array}{l}\text { ti kkkellén } \\
\text { to pparán } \\
\text { to ttaván }\end{array}$ & $\begin{array}{l}\text { 'the head' } \\
\text { 'the money' } \\
\text { 'the stew' }\end{array}$ & $\begin{array}{l}{ }^{*} \text { tin kkkellén } \\
{ }^{\star} \text { ton pparán } \\
{ }^{*} \text { ton ttaván }\end{array}$ \\
\hline
\end{tabular}




\begin{tabular}{|c|c|c|}
\hline \multirow{3}{*}{$\begin{array}{l}\text { ti psačín } \\
\text { ti ksilopaúran } \\
\text { to flókkon }\end{array}$} & 'the poison' & *tin psačín \\
\hline & 'the cold weather' & * tin ksilopaúran \\
\hline & 'the mop' & *ton flókkon \\
\hline ti ðromolakšán & 'the ditch' & *tin ðromolakšán \\
\hline tin krémman & 'the cream' & *ti krémman \\
\hline tin klátsan & 'the sock' & *ti klátsan \\
\hline ton tráullon & 'the billy goat' & * to tráullon \\
\hline ton prúnzon ${ }^{6}$ & 'the bronze' & ${ }^{*}$ to prúnzon \\
\hline ton plátanon & 'the plane tree' & ${ }^{*}$ to plátanon \\
\hline
\end{tabular}

\subsection{Summary}

The geminates of Cypriot Greek exhibit the dual patterning typical of geminates cross-linguistically. With regard to palatalization, geminates act like single segments, since they are completely palatalized in the relevant environment, unlike clusters in which only the second member of the cluster is affected by the process. At the same time, geminates also pattern with some consonant clusters in that they trigger final nasal deletion across word boundaries. Accounting for these apparently conflicting facts is at the core of the analysis presented here.

\section{Accounting for the facts}

The dichotomous pattern exhibited by Cypriot Greek geminates is accounted for in similar but not identical ways under most modern prosodic frameworks, since these models share a basic assumption: that geminates are composed of a melodic root node that is attached to two prosodic positions. However, various frameworks differ as to what these prosodic positions actually are.

As demonstrated below, Hayes' moraic theory (1989) posits that a geminate is a root node which is linked to a mora (an abstract unit of prosodic weight) and to a syllable node. It is this multiple-linking which is assumed to encode phonological length. Crucially, it is also assumed that geminate consonants are multiply-linked to two syllables, implying that geminates only exist in wordmedial environments.

Earlier frameworks, such as those outlined in Clements and Keyser 1983 and Levin 1985, assume that a geminate is a root node linked to two abstract timing units, which in turn may be linked to syllable nodes. Unlike moraic theory, the length of a segment is encoded directly via these timing slots. 
Within this theory, there is no crucial assumption regarding where geminates may surface, since there is no explicit restrictions on where sequences of timing slots may occur.

(6) Representation of geminates in different frameworks

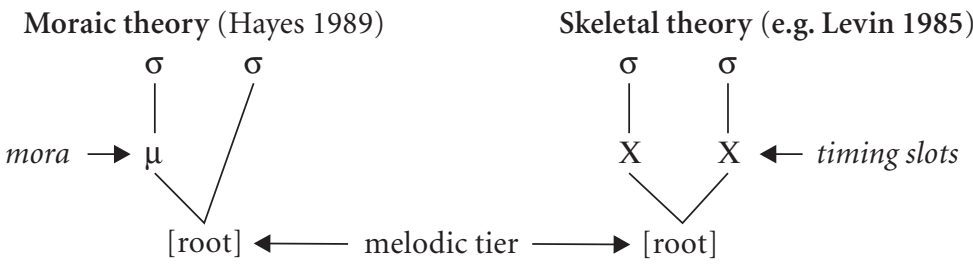

There is a substantial amount of evidence indicating that timing units such as $\mathrm{X}$-slots are superfluous, and that a framework such as Hayes' moraic theory is capable of describing and predicting all prosodic processes (see McCarthy and Prince 1995 for examples and discussion). However, this evidence comes primarily from languages with word-medial geminates. As will be shown below, a framework that lacks explicit representation of timing slots (such as moraic theory) is incapable of treating geminates and consonant clusters as a natural class when they are in word-initial position; conversely, due to the explicit timing features of skeletal frameworks, the like patterning of geminates and clusters is predicted regardless of where they surface in a word. Thus, for Cypriot Greek, in which clusters and geminates pattern alike in the word-initial environment, a skeletal framework is more adept at accounting for this pattern.

\subsection{Background assumptions}

The account of Cypriot Greek presented below follows the assumptions of Clements and Keyser 1983, in which consonants are typically dominated by C timing slots and vowels are usually dominated by $\mathrm{V}$ timing slots. ${ }^{7}$ As shown in (8), a geminate in CV theory is similar to a single consonant in that it has a single root node, and is similar to a consonant cluster in that it occupies two C-slots. It is these structural parallels which allow for a unified account of the geminates in this language. 
(7) CV theory (Clements and Keyser 1983)

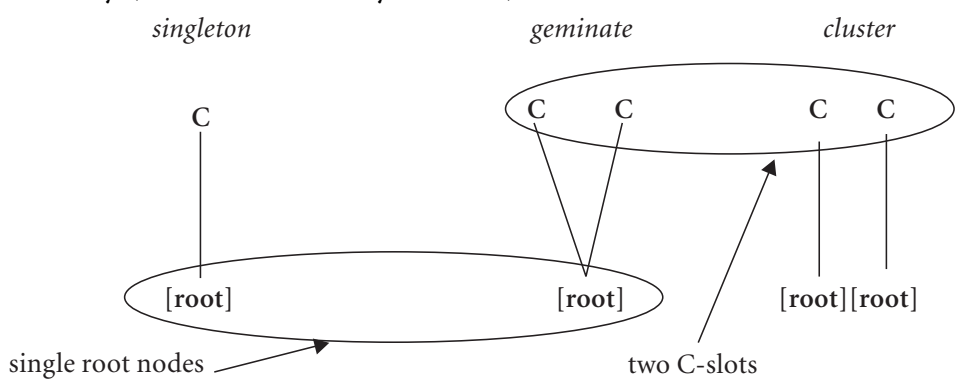

The formal analysis of Cypriot Greek will be presented within Optimality Theory, a constraint-based framework (Prince and Smolensky 1993, McCarthy and Prince 1995). In this framework, multiple potential surface forms are evaluated by a set of universal constraints that have a language-specific ranking.

\subsection{Palatalization and the CV framework}

An account of the palatalization process is straightforward in the CV framework. Recall that single and geminate segments are palatalized before the vowel /i/, while only the second member of a consonant cluster is affected, as repeated below, from (2a).
(8) kakós
'bad (MAsC.sG)'
kačí
'bad (FEM.SG)'
sákkos
'jacket (NOM.sG)'
sáčči
'jacket (NOM.PL)'
cf. marankós 'carpenter (NOM.sG)'
maranči 'carpenter (NOM.PL)'

Under the assumption that geminates have a single root node and thus are single segments, the process can be described as the palatalization of the segment immediately preceding the vowel $/ \mathrm{i} /$, as demonstrated below. Here, as throughout the paper, the root nodes are represented as phonetic symbols in prosodic representations. 
(9) Palatalization:

Palatalization:
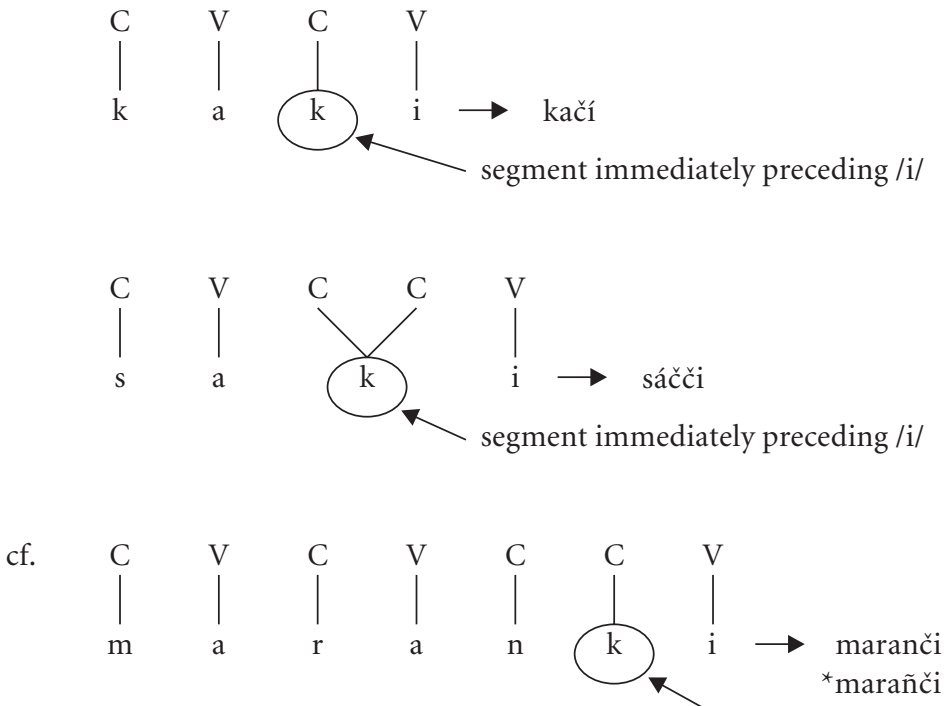

segment immediately preceding /i/

This generalization can be expressed as below. It is assumed that this prohibition against sequences of velars and front vowels operates on the root node level; crucially, since geminates and singletons are both single root nodes, they are expected to pattern in the same manner.

(10) $*[\mathrm{Ki}] \quad$ Root node sequences of velars and /i/ are prohibited ${ }^{8}$

It is assumed that the requirement reflected by this constraint is fairly important in this language since the observed pattern of palatalization is so prevalent; thus, the constraint ${ }^{*}[\mathrm{Ki}]$ is posited to be undominated. Additionally, since an underlying non-palatal consonant may surface as a palatal, it is also safe to assume that a constraint such as FAITH, which prohibits featural changes, is lowly ranked. This is demonstrated in the following tableau. Here, the winning candidate (a) is selected because it only violates the relatively low-ranked FAITH constraint. This violation is incurred because the underlying segment $/ \mathrm{k} /$ is realized as [č] on the surface. Candidate (b) does not incur a violation of FAITH because there have been no changes to the underlying segments. However, this form violates the more highly ranked constraint against sequences of $[\mathrm{k}]$ and [i]. Thus, it is rejected. 
(11) Palatalization

input: /kak-/ 'bad (root)' + /-i/ 'fem. sg. adj. suffix' $\rightarrow$ [kačí]

\begin{tabular}{|l||c|c|}
\hline \multicolumn{1}{|c||}{$/ \mathrm{kak}+\mathrm{i} /$} & ${ }^{*}[\mathrm{Ki}]$ & FAITH \\
\hline \hline a. $\mathrm{kači}$ & & $*$ \\
\hline b. kaki & $* !$ & \\
\hline
\end{tabular}

A form with a geminate consonant is evaluated in exactly the same manner as a singleton, as shown below. Recall that since a geminate consists of a single root node, it is entirely affected by the palatalization process. Since the root node cannot be split, there is no candidate in which the geminate is 'half' palatalized, such as ${ }^{\star}$ sakči.

input: /sakk-/ 'jacket (root)' +/-i/ (nom. pl. suffix) $\rightarrow$ sáčči

\begin{tabular}{|l||c|c|}
\hline \multicolumn{1}{|c||}{$/$ sakk $+\mathrm{i} /$} & $*[\mathrm{Ki}]$ & FAITH \\
\hline \hline a. sačči & & $*$ \\
\hline b. sakki & $* !$ & \\
\hline
\end{tabular}

The surface forms of words with consonant clusters are also correctly predicted by the constraints that have been proposed. As demonstrated below, candidate (a), in which only the segment immediately preceding /i/ is palatalized, is chosen. Candidate (b) violates the constraint against sequences of [Ki]. Candidate (c), in which both of the segments of the cluster have been palatalized, is compared unfavorably to the winning candidate. This is because in (d), two underlying segments have been changed in the surface form, while in (a), only one segment of the cluster has been affected.

(13) input: /pefk-/ 'pine tree (root)' +/-i/ (nom.pl. suffix) $\rightarrow$ péfrci

\begin{tabular}{|l||c|c|}
\hline \multicolumn{1}{|c||}{$/$ pefk $+\mathrm{i} /$} & ${ }^{*}[\mathrm{Ki}]$ & ${ }^{\text {FAITH }}$ \\
\hline \hline a. pefči & & ${ }^{*}$ \\
\hline b. $\quad$ pefki & ${ }^{*} !$ & \\
\hline c. $\quad$ pečči & & ${ }^{*} !^{*}$ \\
\hline
\end{tabular}

In summary, the behavior of geminates with regard to palatalization in Cypriot Greek is accounted for in a straightforward manner: only the segment immediately preceding the vowel /i/ is affected. Since geminates comprise a single root 
node and thus are single segments, they behave as such for this process, and not as consonant clusters.

\subsection{Nasal deletion in the CV framework}

The behavior of geminate consonants with regard to nasal deletion is also explicable within the $\mathrm{CV}$ framework of representation. Recall that word-initial geminates and some initial consonant clusters trigger deletion of a preceding word-final nasal. It is posited that this deletion is driven by a restriction on threeconsonant clusters that applies across word boundaries as well as within words.

As shown below, there are sequences of three consonants that are permitted in Cypriot words, and are found both in words and across a word boundary (such as when the nasal final article tin precedes a word such as 'cream': tin + $\mathrm{kremma} \rightarrow$ tin kremma). In the second group are three-consonant clusters that are never observed in Cypriot, either within words or across word boundaries. It is argued that final nasal deletion occurs in order to avoid the creation of these disallowed clusters (such as in tin + psačin $\rightarrow$ ti psačin, not ${ }^{\star}$ tin psačin).

(14) Three-consonant clusters in Cypriot Greek

a. Allowed: spr, str, skl, mpl, mpr, ntr, nkl, nkr

b. Disallowed: nps, nfl, nks, nðr

While the division between the class of acceptable consonant clusters and the unacceptable ones may appear arbitrary, the pattern becomes apparent when the concept of relative sonority is taken into account. Presented below is a modified sonority scale, based on concepts presented in Zec (1995) and references therein. Each segment class is assigned a number indicating their relative sonority value: stops have a value of 1 , as they are less sonorous than fricatives (with a value of 2), nasals (with a value of 3 ), and liquids (with a sonority value of 4 ).

(15) Relative sonority scale (following Zec 1995 inter alia)

less sonorous Sonority value:

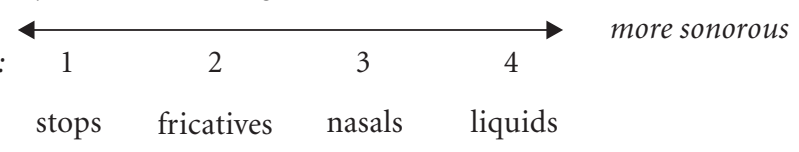

Quantifying relative sonority values permits a clear, descriptive generalization of the three-consonant cluster patterns. Specifically, in the permitted clusters, the relative values of $\mathrm{C} 2$ and $\mathrm{C} 3$ are always 1:4. In the disallowed sequences, C2 and $\mathrm{C} 3$ have different sonority contours. 
With regard to the nasal deletion process outlined earlier, it can be seen that in each cluster that triggers deletion, the sonority values are not 1:4; conversely, the clusters that do not trigger deletion exhibit that exact ratio:

(16) Sonority ratio for clusters:

Examples of no deletion:

tin + kremman [tin kremman]

tin + klatsan [tin klatsan]

Cluster type: ratio:

$\mathrm{kr}$

$\mathrm{kl}$
$1: 4$

$1: 4$
Examples of deletion: ${ }^{9}$

tin + psacin [ti psačin]

ton + flokkon [to flokkon]

Cluster type: ratio:

ps $\quad 1: 2$

fl $\quad 2: 4$

Under the assumption that geminates consist of two C slots, the fact that they pattern like some consonant clusters in triggering deletion is entirely expected: the two Cs have the same sonority value (since they are linked to the same root node), as illustrated below.

(17) Sonority ratio for geminates:

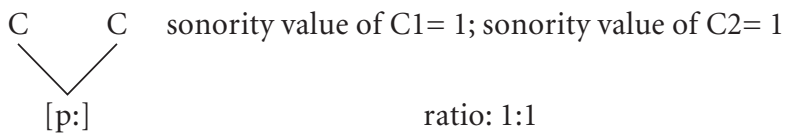

Since the two $\mathrm{C}$ slots associated to the geminate have a sonority ratio value of less than 1:4, they are expected to trigger deletion. As shown below, if the nasal is not deleted, a three-consonant cluster with an unacceptable sonority contour would result:

(18) ton + pparan [to pparan] (sonority of cluster: 1:1) *[ton pparan] (sonority of C2 and C3 in resulting cluster 1:1)

A constraint that captures the generalization about relative sonority values and phonotactic restrictions is shown in (19). Essentially, this constraint prohibits sequences of three consonants in which the relative sonority value of $\mathrm{C} 2$ and $\mathrm{C} 3$ do not fit the allowable 1:4 ratio. ${ }^{10}$ Since this constraint results in deletion of the final nasal of the articles /tin/ and /ton/, it is apparent that it dominates the universal MAX constraint which penalizes segment deletion.

(19) ${ }^{\star}$ CCC Sequences of three consonants in which the relative sonority values of $\mathrm{C} 2$ and $\mathrm{C} 3$ are not 1:4 are not permitted.

MAX No deletion

As demonstrated in the following tableau, the combination of these constraints 
leads to final nasal deletion before all consonant clusters except those consisting of a stop + liquid combination (i.e. those that have the 1:4 ratio).

In Tableau 20 (i), a form with a stop + liquid cluster is evaluated. The winning candidate does not incur any violations. Candidate (b) incurs a violation of the MAX constraint since the nasal has been deleted.

In tableau (ii), a word with a deletion-triggering onset is evaluated. The winning candidate (a) incurs a violation of the MAX constraint, since the nasal has been deleted. However, this is a necessary violation, since a three-consonant sequence with a disallowable sonority contour would otherwise result, as in candidate (b).

Tableau (iii) evaluates a form with an initial geminate. The winning candidate incurs a violation of MAX, since again, the nasal is deleted. As in the previous tableau, if the segment were not deleted, a sequence of three consonants with an undesirable sonority contour would result.

(20) i. no deletion

\begin{tabular}{|l||c|c|}
\hline \multicolumn{1}{|c||}{$/$ tin + klatsan/ } & ${ }^{*} \mathrm{CCC}$ & MAX \\
\hline \hline a. ${ }^{*}$ tin klatsan & & \\
\hline b. $\quad$ ti klatsan & & $* !$ \\
\hline
\end{tabular}

ii. deletion before cluster with unacceptable sonority ratio

\begin{tabular}{|l||c|c|}
\hline \multicolumn{1}{|c||}{$/$ tin + psačin/ } & ${ }^{*}$ CCC & MAX \\
\hline \hline a. ${ }^{*}$ ti psačin & & $*$ \\
\hline b. tin psačin & ${ }^{*}$ & \\
\hline
\end{tabular}

iii. deletion before geminate

\begin{tabular}{|l||c|c|}
\hline \multicolumn{1}{|c||}{$/$ ton + pparan/ } & ${ }^{*} \mathrm{CCC}$ & MAX \\
\hline a. to pparan $^{*} \quad{ }^{\star}$ & & \\
\hline b. ton pparan & $*$ & \\
\hline
\end{tabular}

The preceding analysis demonstrates that in the CV framework, the facts of nasal deletion can be described in a unified manner. This is because both consonant clusters and geminates are treated as a natural class within this framework: they each consist of two $\mathrm{C}$ slots. Thus, nasal deletion can be described simply as a process that is triggered by two consonants that have a certain sonority ratio. As will be illustrated in the following section, the facts of 
nasal deletion are not explained in as straightforward a manner within the framework of moraic theory, since initial geminates and clusters are not represented in the same way.

\subsection{Accounting for Cypriot Greek in moraic theory}

Moraic theory (Hayes 1989, inter alia) cannot account for the facts of Cypriot Greek in as elegant a manner because under this framework, word-initial geminates and consonant clusters are represented differently. As demonstrated in the first row of the table below, in CV theory geminates and clusters have the same representation regardless of their environment in the word. In each case, both the geminate and the cluster comprise a sequence of two C-slots.

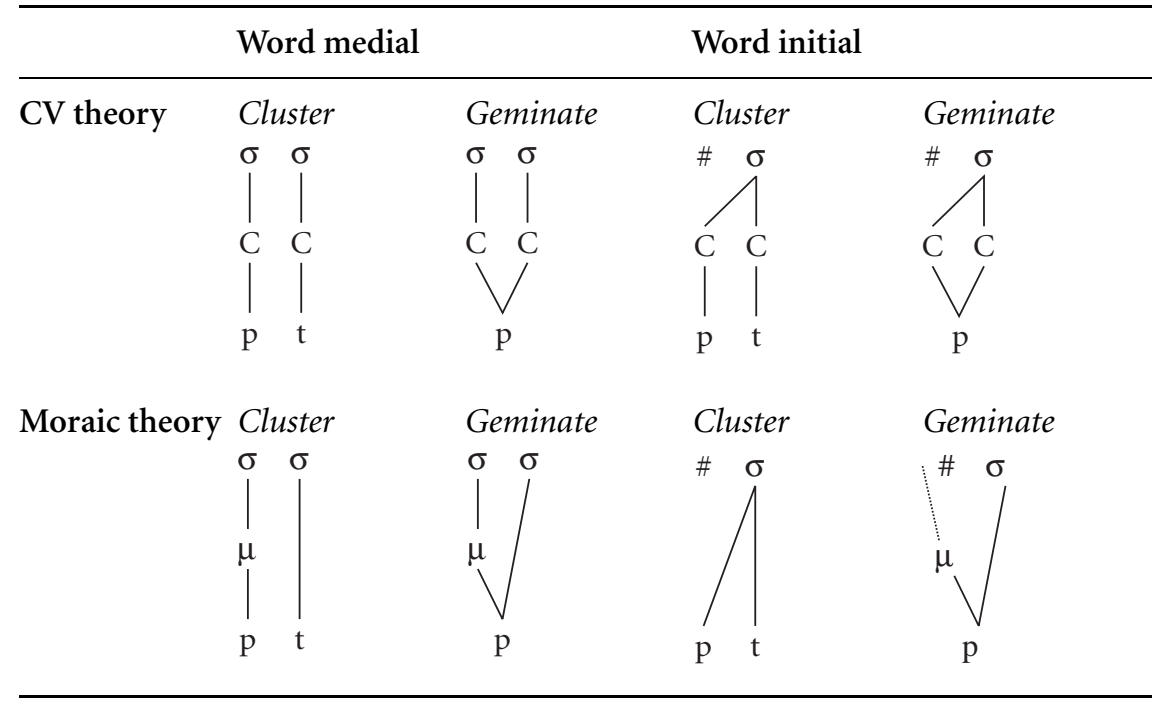

The representations under moraic theory are not as consistent. In this theory, geminates are assumed to be inherently moraic, and so bear a mora in all environments. Other consonants may be assigned a mora, but only in syllable codas. Thus, word-medial geminates and consonant clusters have a similar representation, in that both contribute prosodic weight to the preceding syllable.

It is in word-initial position that the representation of geminates and clusters crucially differs under moraic theory. While the geminate bears a mora, the cluster cannot since there is no process which would result in the assignment of a mora to an initial segment. Due to this representational difference, word-initial clusters and geminates cannot be referred to as a natural class in moraic theory. 
Both moraic and timing-slot theories are similar in that both assume that geminates are single root nodes. Thus, the account of palatalization is identical in both frameworks. Essentially, the root node immediately preceding the triggering vowel is subject to palatalization. However, the lack of parallel structure between initial geminates and clusters in moraic theory means that there is no way to account for a process such as nasal deletion in a unified manner.

For example, it is possible to assume that the sonority constraint described earlier motivates deletion before consonant clusters (with minor revisions, so that the constraint targets root nodes with certain sonority features, not C-slots). Just as in the CV analysis, when this constraint dominates the prohibition against deletion, final nasal deletion before clusters is predicted, as demonstrated in the sample tableau.

Deletion before consonant clusters:

${ }^{*}[\mathrm{rt}][\mathrm{rt}][\mathrm{rt}]$ Clusters of three root nodes which dominate consonantal features (i.e. clusters of three consonants), in which the sonority values of the second and third root nodes are not 1:4, are prohibited.

\begin{tabular}{|l||c|c|}
\hline \multicolumn{1}{|c||}{$/ \mathrm{tin}+\mathrm{psacin} /$} & ${ }^{*}[\mathrm{rt}][\mathrm{rt}][\mathrm{rt}]$ & MAX \\
\hline \hline a. ti psačin $^{*}$ tin psačin & $* !$ & $*$ \\
\hline b. & & \\
\hline
\end{tabular}

Naturally, the same constraint will not predict deletion before geminates, since geminates comprise a single root node. In fact, there is no constraint that can predict deletion before both geminates and clusters, since they have fundamentally different structures in moraic theory. Thus, it is necessary to posit an independent constraint to account for geminate-triggered deletion.

One possible way to account for the behavior of geminates with regard to nasal deletion is to rely upon independent patterns in the language. For example, it is observed that only one consonant is ever allowed word-finally. This may indicate a general restriction against coda clusters, as reflected below:

$$
\begin{aligned}
\left.{ }^{*}[\mathrm{rt}][\mathrm{rt}]\right] \sigma \quad \begin{array}{l}
\text { A sequence of root nodes that dominate consonantal features } \\
\text { (i.e. a sequence of consonants) in a syllable coda is disallowed. }
\end{array}
\end{aligned}
$$

Furthermore, a basic tenet of moraic theory is that the mora cannot occur in syllable onsets. This restriction is represented below.

(24) ${ }^{\star}$ Moraic onset $\quad$ Moraic onsets are prohibited 
These two constraints conspire to trigger deletion, as shown in the following tableau. As can be seen, when the word-final nasal and the first part of the geminate consonant constitute a syllable coda, as in candidate (a), the coda cluster constraint is fatally violated. Likewise, when the geminate is syllabified entirely as the syllable onset, as in (b), the onset constraint is fatally violated, since the onset is then moraic. It is only when the final nasal is deleted that the geminate can be syllabified in a way that satisfies both constraints

(25) Final nasal deletion before geminates

\begin{tabular}{|l||c|c|c|}
\hline \multicolumn{1}{|c||}{ /ton + pparan/ } & ${ }^{\star}$ Moraic Onset & $*$ $[\mathrm{rt}][\mathrm{rt}]] \sigma$ & MAX \\
\hline \hline a. tonp.paran & & $* !$ & \\
\hline b. ton.pparan & $* !$ & & \\
\hline c. top.paran & & & $*$ \\
\hline
\end{tabular}

Syllable structure of candidates:

a.
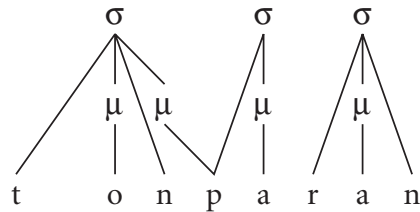

[tonp.paran]

b.
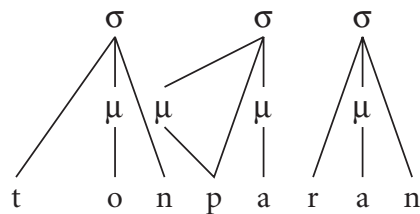

[ton.pparan]

c.
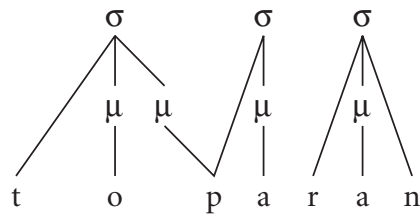

[tonp.paran]

Thus, it is possible to account for the pattern of nasal deletion while maintaining the assumptions of moraic theory. ${ }^{11}$ However, two different principles must be posited to account for the process. In the case of deletion before geminates, the triggering environment is defined in prosodic terms: nasals are deleted before moraic consonants. In the other case of deletion, the triggering environment is defined in melodic terms: nasals are deleted before sequences that have a certain 
relative sonority. These two principles are entirely independent of each other, and so it is impossible to describe the nasal deletion process as affecting a natural class of segments.

In addition to the fact that there are two independent processes driving deletion, it is important to note that in order for the grammar to obtain the correct surface form, the constraint that triggers deletion before clusters (specifically, the ${ }^{*}[\mathrm{rt}][\mathrm{rt}][\mathrm{rt}]$ constraint) and the constraints that trigger deletion before geminates (the ${ }^{\star}$ Moraic onset and $\left.{ }^{\star}[\mathrm{rt}][\mathrm{rt}]\right] \sigma$ constraints) must always be undominated, as they were in the tableaux (22) and (25).

Furthermore, in order for geminates and clusters to pattern together as a natural class, these constraints must have the same exact ranking: when they are undominated, both geminates and clusters trigger deletion. In another language, these constraints might be lowly ranked, meaning that neither geminates nor clusters trigger deletion. Again, this ranking would ensure that the segments act as a natural class.

However, a basic tenet of Optimality Theory is that in general, independent constraints may exhibit any ranking depending upon language-specific requirements. Thus, the constraints posited here could exhibit dissimilar rankings. For example, one possible ranking is that the constraints against coda clusters are very low, while the others are undominated. The result of this ranking is a language in which clusters trigger deletion, while geminates do not, as shown in the following sample tableaux. This is an unattested pattern, and the fact that it is predicted within the moraic model indicates the inherent problems of this framework.

(26) Unattested pattern predicted by possible constraint ranking:

Deletion before cluster, due to high ranking of constraint against threeconsonant clusters:

\begin{tabular}{|l||c|c|}
\hline$/$ tin + psačin/ & ${ }^{*}[\mathrm{rt}][\mathrm{rt}][\mathrm{rt}]$ & MAX \\
\hline \hline ti psačin & & $*$ \\
\hline tin psačin & ${ }^{*} !$ & \\
\hline
\end{tabular}


No deletion before geminate, due to low ranking of constraint against coda clusters:

\begin{tabular}{|c||c|c|}
\hline /ton + pparan/ & MAx & $\left.{ }^{*}[\mathrm{rt}][\mathrm{rt}]\right] \sigma$ \\
\hline \hline tonp.paran & & $*$ \\
\hline to p.paran & $* !$ & \\
\hline
\end{tabular}

To summarize and clarify the problem, within moraic theory, word-initial geminates and clusters are represented differently due to the basic assumptions of this framework. Since the geminates and clusters are not represented in a similar way, it is impossible to account for their similar patterning based only upon their structure (in contrast to the skeletal frameworks). In order to account for their patterning, it is necessary to posit two different types of rules or constraints: one that targets geminates, and one that targets clusters. It is also necessary to posit that both of these constraints are equally active in the language; otherwise, an unattested pattern (such as geminates and clusters patterning differently with regard to deletion) is predicted. It is argued that these crucial stipulations illustrate that moraic theory is inefficient in accounting for the facts of Cypriot Greek.

\section{Conclusion}

As was demonstrated, there is a fundamental difference in how CV theory and moraic theory account for final nasal deletion in Cypriot Greek. In the timingslot approach, deletion occurs before two $\mathrm{C}$ slots that have a certain sonority contour. Both geminates and clusters fit this description, and so are predicted to pattern alike. In the moraic framework, it is necessary to posit two independent constraints that lead to nasal deletion, because consonant clusters and geminates have different prosodic representations in this theory. Thus it is concluded that the CV framework provides a superior account of the facts.

It is important to note that the discrepancy between these two theories is revealed only by investigating the behavior of clusters and geminates in wordinitial position, because it is only in this environment that the frameworks diverge with regard to the representation of geminates and clusters (as was demonstrated in the chart comparing the representations of the two frameworks). Therefore, it is apparent the investigation of a language such as Cypriot Greek is crucial to our understanding of phonological structure. 
It is also important to note that while it is possible to posit constraints that account for final nasal deletion within a moraic framework, these constraints are independent of each other, and so it is only via stipulation that the constraints work together to result in deletion before both geminates and clusters. As was suggested, a simple re-ranking of the constraints results in an unattested situation in which geminates and clusters do not pattern alike. Within the CV framework however, there is a single constraint that targets CC sequences, thus affecting both geminates and clusters. Thus, there is no ranking that would result in an unattested situation: in every case, the geminates will behave as clusters do for processes that target segment quantity, such as the deletion process described here. Since geminates and clusters pattern alike crosslinguistically for such processes, this appears to be a favorable aspect of this framework.

Although a timing-slot framework is demonstrated to be superior in predicting the behavior of word-initial geminates and clusters in Cypriot Greek, it is not suggested that moraic theory be rejected altogether. The insights afforded by this theory, specifically with regard to weight-based prosodic processes are fundamental to our understanding of phonology. Furthermore, the ability of moraic theory to predict prosodic processes (such as compensatory lengthening) cannot be duplicated by a segmental framework, as discussed in Hayes (1989). Conversely however, the results of the analysis of Cypriot Greek imply that timing units such as C-slots also play a crucial role in phonological processes that cannot be duplicated by moraic structure, a finding also supported by languages such as Leti (Hume, Muller and van Engelenhoven 1997), as well as other languages in which geminates pattern as non-moraic (Tranel, 1991). Since neither framework can subsume the other, it is suggested that the basic components of both play a fundamental role in phonological representation (see Muller 2001b).

\section{Notes}

* I am extremely grateful for the helpful and explicit comments of an anonymous reviewer of an earlier draft of this paper, as well as the comments and suggestions of Brian Joseph, Elizabeth Hume O'Haire, Georgios Tserdanelis, and Gaberell Drachman, and participants at the 2000 Greek dialectology conference in Patras, Greece. Additionally, I thank Eliza Pitri for her help as a language informant.

1. The phonetic extent of the palatalization may vary between speakers; some produce a segment closer in articulation to the palatal-alveolar affricate /č/, while others produce a 
fronted velar segment $/ \mathrm{k} /$. Regardless of the realization, the point remains the same: only the segment preceding the vowel /i/ is subject to palatalization.

2. It has been suggested that the $[\mathrm{pk}]$ sequence is derived from underlying / $/ \mathrm{pj} /$, suggesting that $[\mathrm{pk}]$ is perhaps not representative of allowable clusters in Cypriot. However, the lack of surface alternations between $/ \mathrm{pj} /$ and $/ \mathrm{pk} /$ leave the origin of this cluster in doubt.

3. Drachman and Malikouti-Drachman (1997) propose that this alternation is the result of a restriction on the realization of syllable codas. However, this constraint produces the same result as the restriction on stop clusters: sequences of stop + stop are dispreferred in Cypriot.

4. The second and third examples also illustrate the deletion of nasals in tri-consonantal clusters, a process which is independent of lenition but which will be described in more depth later in the paper.

5. Coda nasals undergo place assimilation, a process that is independent of the deletion process to be described here. The point remains that the nasal is not deleted.

6. It has been suggested that this word is best transcribed with an epenthetic voiced stop: [prundzon]; the amount of obstruentization observed in this cluster appears to vary between speakers. In any case, the presence or absence of the stop is irrelevant to the current analysis, since the word-internal clusters do not affect final nasal deletion.

7. While the generalizations afforded by Levin's 1985 framework, in which all segments are dominated by a generic X timing slot, are important, the CV framework is adopted for ease of exposition. Both frameworks can describe the facts equally well, under the assumption that 'C-slot' is functionally equivalent to ' $\mathrm{X}$-slot that dominates a root node with consonantal features'.

8. Palatalization of segments is not limited to velars, nor triggered solely by the vowel /i/; alveolars are also targeted when they are followed by a sequence of /i/ followed by another more sonorous vowel, and /e/ can also trigger palatalization. This constraint is intended to reflect one component of this general pattern.

9. Naturally, deletion of any one of the segments in the sequence would result in an acceptable form, since two-consonant clusters are subject to few restrictions: the / $\mathrm{np} /$ of the possible form [tin pačin] is not disallowed. However, evidence from other languages (Beckman 1997) indicates that there is a cross-linguistic tendency to preserve segments that occur at the beginnings of words. It is posited that in Cypriot, the deletion of the word-final nasal, instead of the word-initial segment, reflects this tendency.

10. It is plausible that this restriction on consonant sequences could be framed as a syllable structure constraint, e.g. 'onset clusters must have a certain sonority ratio'. However, lack of satisfactory independent evidence regarding syllabification of tri-consonantal sequences makes this option less favorable than simple evaluating the sonority contour of two consonants, regardless of their syllabification.

11. Obviously, this potential analysis within the moraic framework ignores many interesting points regarding the representation of syllable-initial geminates in this theory; the examples given here are intended to demonstrate one manner of accounting for the pattern. For further discussion and analysis, the reader is referred to Hume, Muller and van Engelenhoven (1997), Davis (1999), and Muller (2001b). 


\section{References}

Abramson, Arthur. 1992. "Amplitude as a cue to word-initial consonant length: Pattani Malay”. Haskins Laboratories Status Report on Speech Research. SR-109/110 pp. 251-254. New Haven, Connecticut.

Anderson, Gregory. 1997. "Lak Phonology". Phonologies of Asia and Africa (including the Caucasus). Alan S. Kaye, ed. Eisenbrauns, Winona Lake, Indiana.

Arvaniti, Amalia. 2001. "Cypriot Greek and the phonetics and phonology of geminates". Proceedings of the First International Conference of Modern Greek Dialects and Linguistic Theory. University of Patras, Patras, pp. 19-29.

Arvaniti, Amalia. \& Giorgos Tserdanelis. 2000. “On the phonetics of geminates: evidence from Cypriot Greek”. Proceedings of the International conference on Spoken Language Processing (ICSLP 2000) vol. 2: 559-562. Beijing.

Beckman, Jill. 1997. "Positional faithfulness, positional neutralization and Shona vowel harmony". Phonology 14 . 1-46.

Broselow, Ellen, Su-i Chen, \& Marie Huffman. 1997. "Syllable weight: the convergence of phonology and phonetics". Phonology 14. 47-82.

Carlyle, Karen 1988. A syllabic phonology of Breton. PhD. dissertation. University of Toronto. Clayre, Iain. 1973. "The phonemes of Sa'ban: a language of Highland Borneo". Linguistics 100: $26-46$.

Clements, George N. 1986. "Compensatory lengthening and consonant gemination in LuGanda”. Studies in compensatory lengthening. Wetzels, L. and E. Sezer eds. Dordrecht: Foris Publications.

Clements, George. N. \& Jay Keyser. 1983. CV Phonology. MIT Press, Cambridge, Massachusetts. Cohen, Patrick. 1965. "Presyllables and reduplication in Jeh". Mon-Khmer studies II. 31-40. Davis, Stuart. 1999. "On the representation of initial geminates". Phonology 16.

Dell, Francois. \& Mohamed Elmedlaoui. 1985. "Syllabic consonants and syllabification in Imdlawn Tashlhiyt Berber”. Journal of African Languages and Linguistics. 7.105-130.

Drachman, Gaberell \& Angeliki Malikouti-Drachman. 1997. 'Dissimilation in Cypriot Greek: competing analyses”. Studies in Greek Linguistics 17. 42-57.

Giagoulles, Konstantinos, 1994. Etymological and lexical dictionary of the Cypriot dialect. \#54 Library of Cypriot folk poets. Nicosia.

Goodenough, Ward \& Hiroshi Sugita. 1990. Trukese-English Dictionary - Supplemenatry Volume. The American Philosophical Society, Philadelphia.

Ham, William. 1999. Phonetic and phonological aspects of geminate timing. PhD. dissertation, Cornell.

Hamp, Eric. 1961. “On so-called gemination in Greek”. Glotta 39. 265-268.

Hayes, Bruce. 1989. "Compensatory lengthening in moraic phonology". Linguistic Inquiry 20. 253-306.

Hewitt, B. George. 1995. Georgian: a structural reference grammar. London Oriental and African language library. vol 2.

Hume, Elizabeth, Jennifer Muller, \& Aone van Engelenhoven. 1997. "Non-moraic geminates in Leti”. Phonology 14. 371-402.

Levin, Juliette. 1985. A metrical theory of syllabicity. PhD. dissertation, MIT. 
Malikouti-Drachman, Angeliki. 1987. "The representation of double consonants in Cypriot Greek”. Studies in Greek Linguistics 8. 275-291.

McCarthy, John \& Alan Prince. 1995. "Prosodic morphology". The handbook of phonological theory. J. Goldsmith, ed. Blackwell Publishers, Oxford, pp.318-366.

Muller, Jennifer. 1999. "A unified-mora account of Chuukese". Proceedings of West Coast Conference on Formal Linguistics, 18.

Muller, Jennifer. 2001a. "Theoretical Implications of Initial Geminates in Cypriot Greek". Proceedings of the First International Conference of Modern Greek Dialects and Linguistic Theory. University of Patras, Patras, pp. 177-191.

Muller, Jennifer. 2001b. The phonology and phonetics of word-initial geminates. PhD. dissertation, The Ohio State University.

Newton, Brian. 1967. “The phonology of Cypriot Greek”. Lingua 18. 384-411.

Newton, Brian. 1972. Cypriot Greek: its phonology and inflections. Mouton, The Hague.

Niang, Mamadou. 1997. Constraints on Pulaar phonology. University Press of America.

Prince, Alan \& Paul Smolensky. 1993. Optimality theory: constraint interaction in generative grammar”. Ms., Rutgers University and University of Colorado, Boulder.

Tranel, Bernard. 1991. "CVC light syllables, geminates and moraic theory". Phonology 8. 291-302.

Tserdanelis, Giorgos \& Amalia Arvaniti. 2001. “The acoustic characteristics of geminate consonants in Cypriot Greek". Proceedings of the fourth international conference on Greek linguistics. University Studio Press.

van Engelenhoven, Aone. 1995. A description of the Leti language (as spoken in Tukukei). $\mathrm{PhD}$ dissertation, University of Leiden.

Zec, Draga. 1995. “Sonority constraints on syllable structure”. Phonology 12.

\section{$\Pi \varepsilon \rho \iota \eta ́ \psi \eta$}

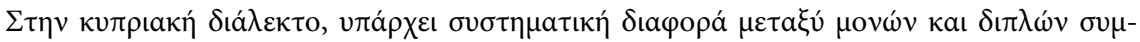

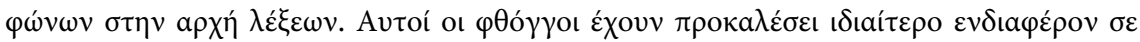

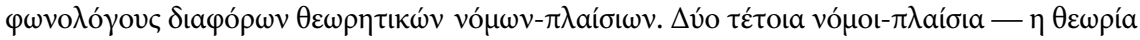

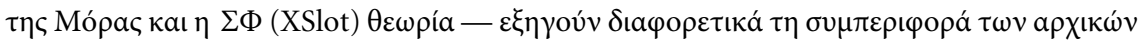

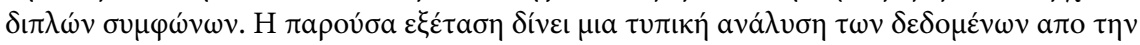

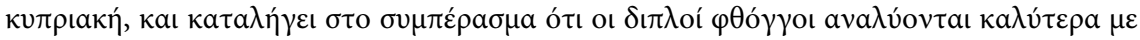

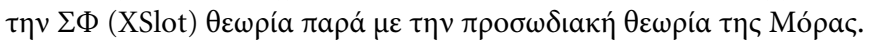

